\title{
S4 Text
}

\section{The Priming Questionnaire}

To assess the efficacy of the priming a questionnaire was administered after the exposure that consisted of a set of 7 questions that assessed the degree of identification with science, and a further 5 questions to that assessed the degree of identification with students.

Table 1. Items Used to Assess Priming Efficacy.

\begin{tabular}{|l|l|}
\hline Variable name & Question \\
\hline sci1 & I feel good about furthering psychological science \\
\hline sci2 & I identify with the researchers who designed this study \\
\hline sci3 & I identify with the goals of psychological science \\
\hline sci4 & I feel positive about the scientists behind this research \\
\hline sci5 & I feel strong ties with people who are pro-science. \\
\hline sci6 & I think of myself as part of the pro-science community \\
\hline sci7 & I identify with supporters of science. \\
\hline & \\
\hline nsc1 & I identify with the learner in this study \\
\hline nsc2 & I fell positive about the learner in this study \\
\hline nsc3 & I feel strong ties with other students living in London. \\
\hline nsc4 & I think of myself as part of the student community in London. \\
\hline nsc5 & I identify with other students living in London \\
\hline
\end{tabular}

Each item was scored on a 1-7 scale, with 1 indicating no agreement and 7 indicating complete agreement.

In order to obtain one overall score for each of these we used polychoric principal components analysis [32]. This is a principal components analysis for ordinal scales, assuming that the ordinal scales are samples from an underlying continuous (latent) variable. In the case of Science 
the first principle component (ysci) explained 57\% of the variation in the 7 ordinal scores.

Similarly the first principal component for the Students scores (ynsc) explained $58 \%$ of the variation of the 5 scores.

\section{Table 2. Correlations for the Priming Scores}

\begin{tabular}{|l|l|l|}
\hline Variable & $\begin{array}{l}\text { Spearman Correlation with } \\
\text { ystu }(\mathrm{n}=40)\end{array}$ & $\begin{array}{l}\text { Spearman correlation with } \\
\text { ysc }(\mathrm{n}=40)\end{array}$ \\
\hline nsc1 & 0.34 & \\
\hline nsc2 & 0.18 & \\
\hline nsc3 & 0.89 & \\
\hline nsc4 & 0.94 & \\
\hline nsc5 & 0.90 & \\
\hline sci1 & & 0.62 \\
\hline sci2 & & 0.44 \\
\hline sci3 & & 0.50 \\
\hline sci4 & & 0.55 \\
\hline sci5 & & 0.92 \\
\hline sci6 & & 0.93 \\
\hline sci7 & & 0.94 \\
\hline
\end{tabular}

